\title{
Synchronization methods for chaotic systems involving fractional derivative with a non-singular kernel.
}

\author{
Fatiha Mesdoui ${ }^{1}$, Nabil Shawagfeh ${ }^{2}$, and Adel Ouannas ${ }^{3}$ \\ ${ }^{1}$ Amman Arab University \\ ${ }^{2}$ The University of Jordan \\ ${ }^{3}$ University of Tebessa Faculty of Exact Sciences and Natural and Life Sciences
}

November 30, 2020

\begin{abstract}
This study considers the problem of control-synchronization for chaotic systems involving fractional derivative with a nonsingular kernel. Using an extension of the Lyapunov Theorem for systems with Atangana-Baleanu-Caputo (ABC) derivative, a suitable control scheme is designed to achieve matrix projective synchronization (MP) between nonidentical ABC systems with different dimensions. The results are exemplified by the ABC version of the Lorenz system, Bloch system, and Liu system. To show the effectiveness of the proposed results, numerical simulations are performed based on the Adams-Bashforth-Mounlton numerical algorithm.
\end{abstract}

\section{Hosted file}

Main docum.pdf available at https://authorea.com/users/380058/articles/496194synchronization-methods-for-chaotic-systems-involving-fractional-derivative-with-anon-singular-kernel 
(a)

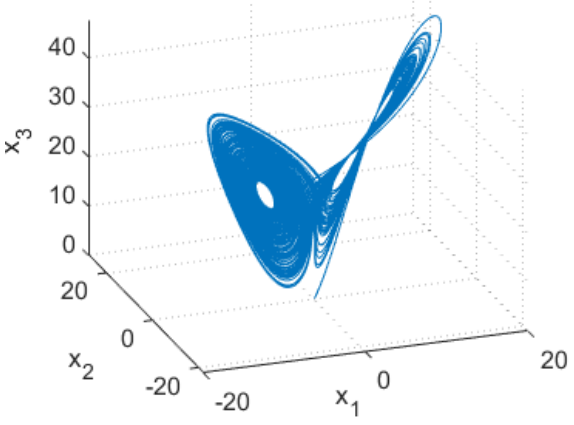

(c)

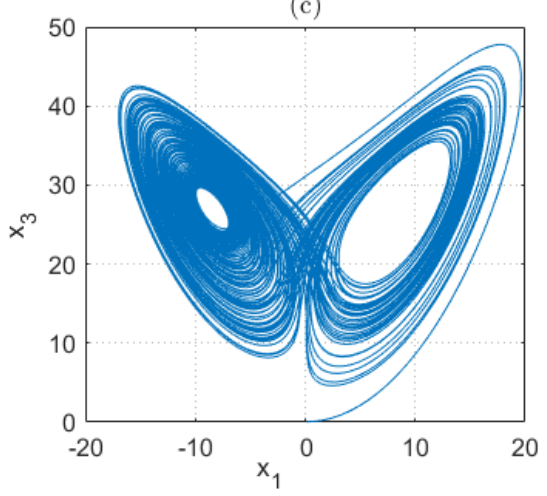

(a)

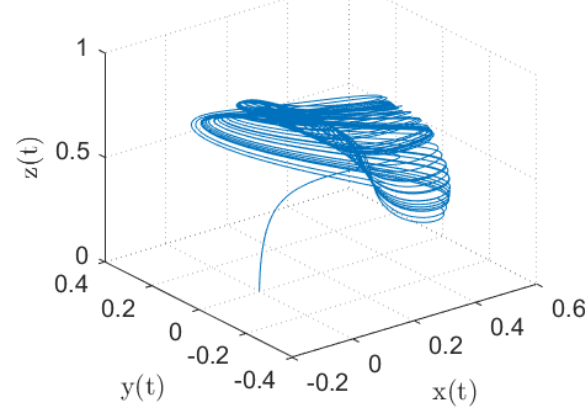

(c)

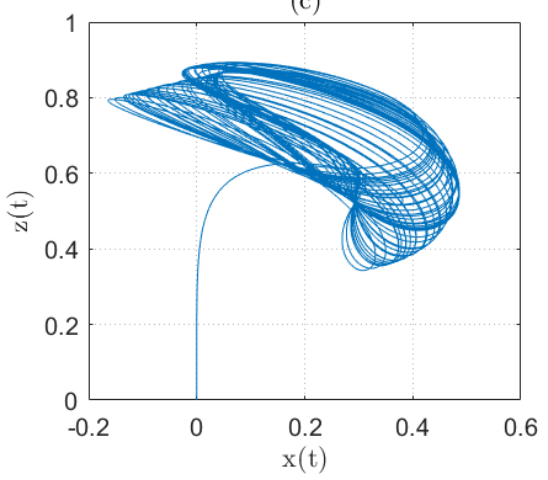

(b)

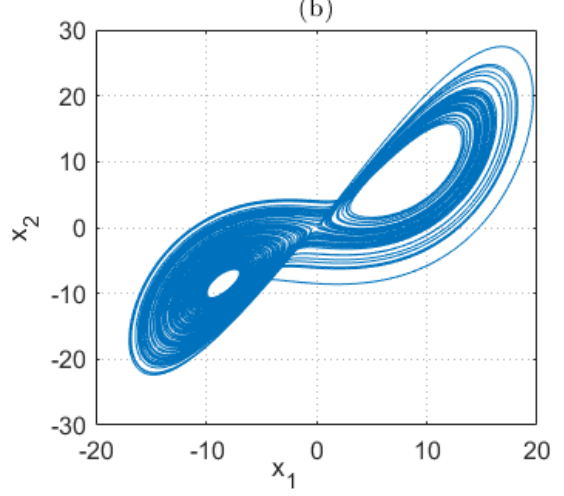

(d)

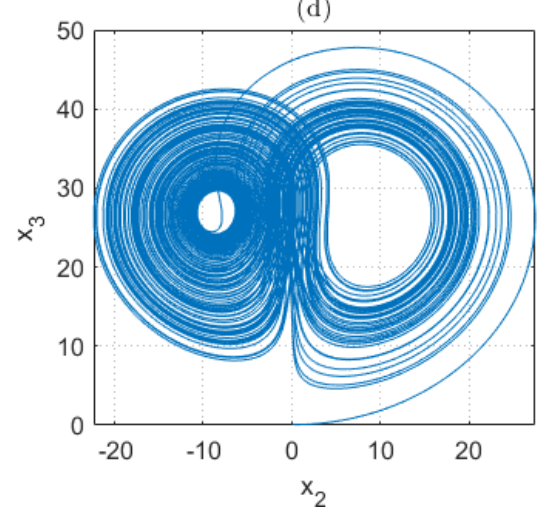

(b)

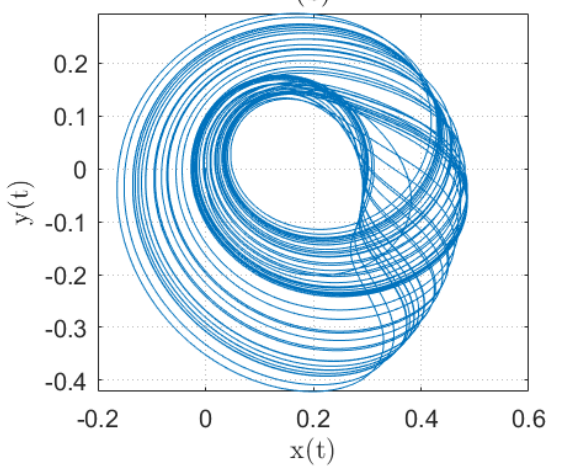

(d)

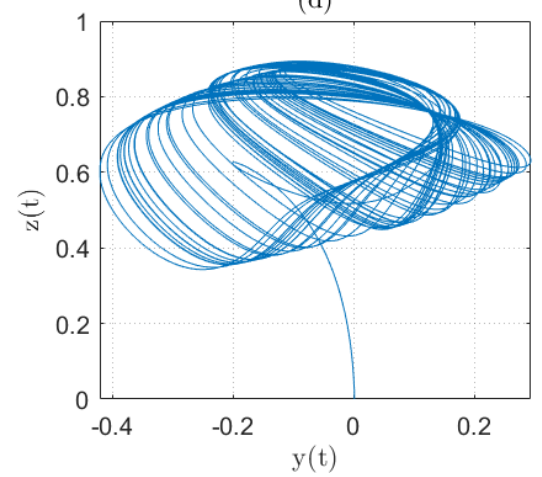




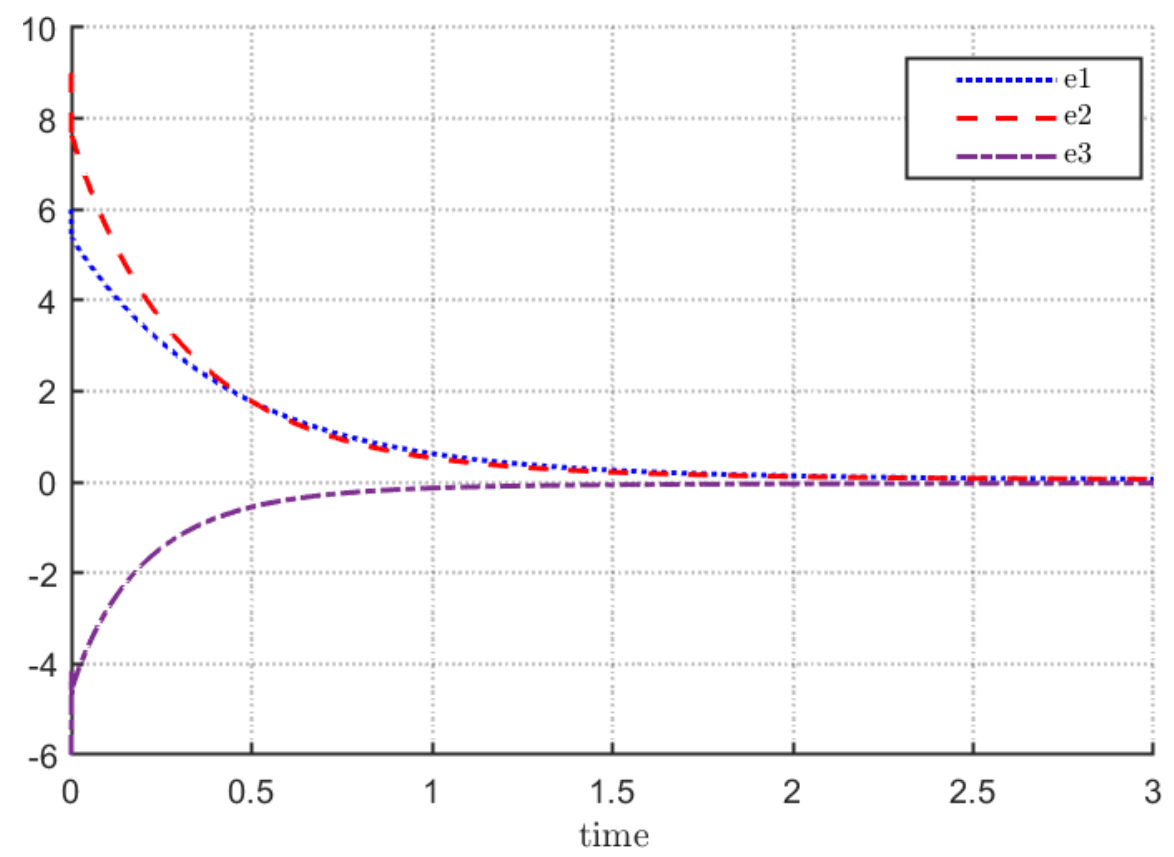

(a)

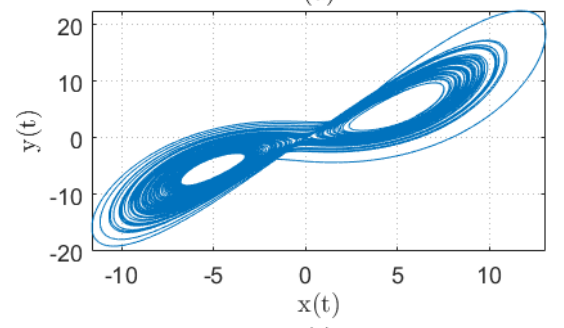

(c)

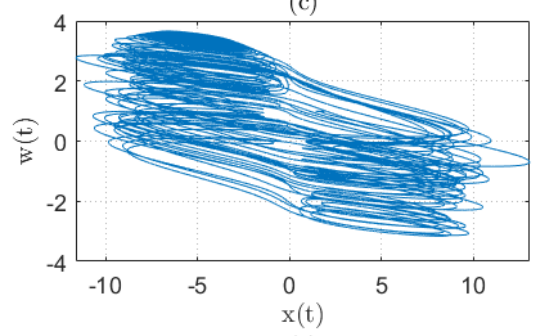

(e)

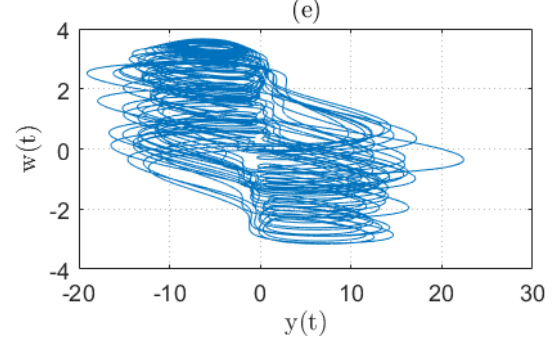

(b)

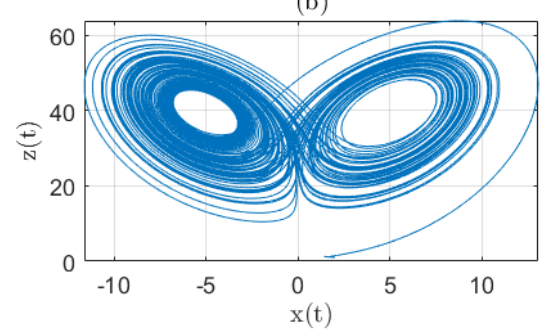

(d)

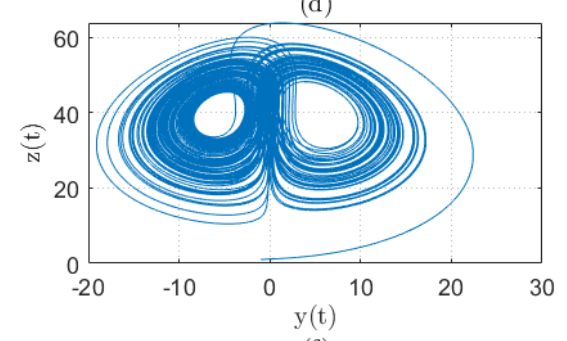

(f)

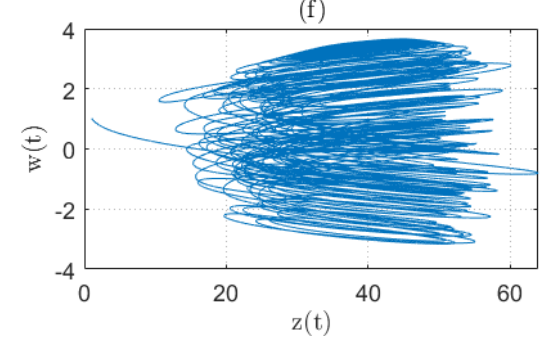




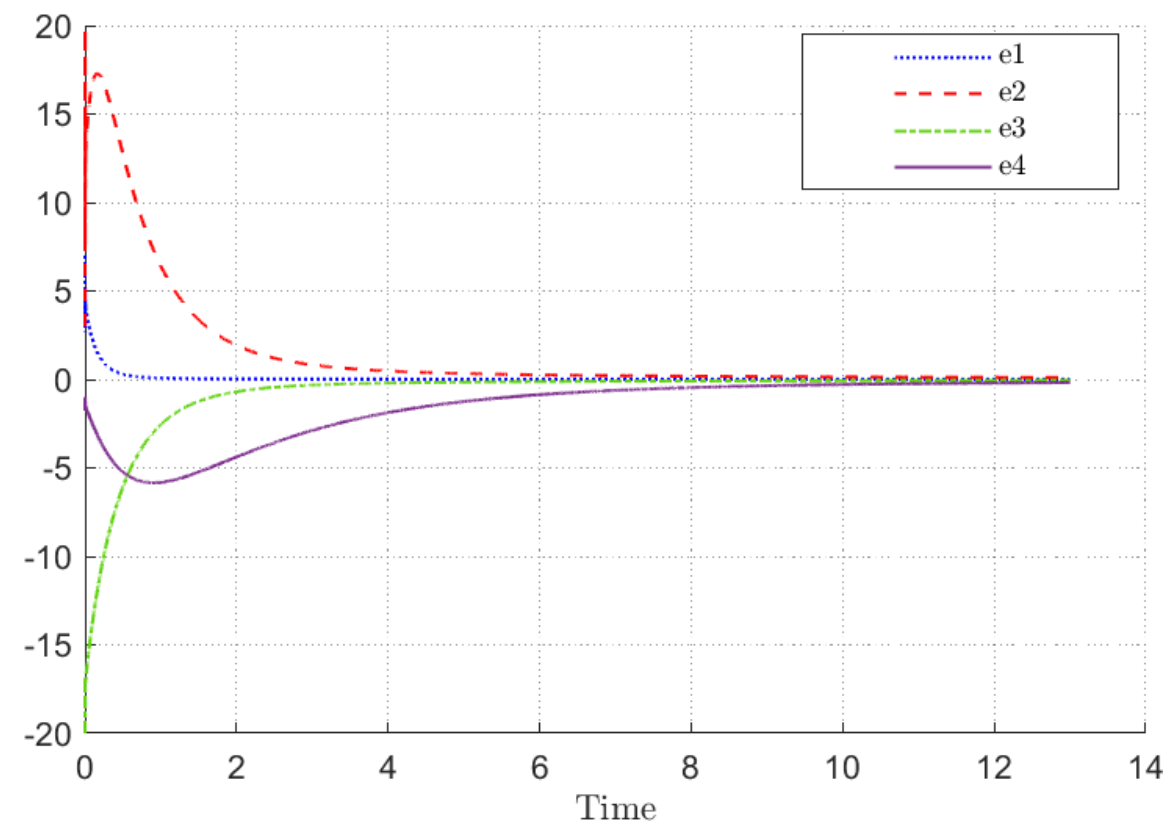

